\title{
Agreement between fragility fracture risk assessment algorithms as applied to adults with chronic spinal cord injury
}

\author{
T Cervinka ${ }^{1}$, CL Lynch ${ }^{2,3}$, L Giangregorio ${ }^{2,3}$, JD Adachi ${ }^{4}$, A Papaioannou ${ }^{4,5}$, L Thabane ${ }^{5}$ and BC Craven ${ }^{1,2,3,6}$
}

\section{Study design: Cross-sectional.}

Objectives: The objective of the study was to determine and report agreement in fracture risk stratification of adults with spinal cord injury (SCI) using (1) Canadian Association of Radiologists and Osteoporosis Canada (CAROC) and Canadian Fracture Risk Assessment (FRAX) tools with and without areal bone mineral density (aBMD) and (2) SCl-specific fracture thresholds.

Setting: Tertiary rehabilitation center, Ontario, Canada.

Methods: Community-dwelling adults with chronic SCI ( $n=90, \mathrm{C} 2-\mathrm{T} 12$, AIS A-D) consented to participation. Femoral neck aBMD values determined 10-year fracture risk (CAROC and FRAX). Knee-region ABMD and distal tibia volumetric BMD values were compared to SCl-specific fracture thresholds. Agreements between CAROC and FRAX risk stratifications, and between fracture threshold risk stratification, were assessed using prevalence- and bias-adjusted Kappa statistics (PABAK).

Results: CAROC and FRAX assessment tools showed moderate agreement for post-menopausal women (PABAK $=0.56,95 \%$ confidence interval $(\mathrm{Cl}): 0.27,0.84)$ and men aged $\geqslant 50$ years (PABAK $=0.51,95 \% \mathrm{Cl}: 0.34,0.67$ ), with poor agreement for young men and pre-menopausal women (PABAK $\leqslant 0)$. Excellent agreement was evident between FRAX with and without aBMD in young adults and in those with motor incomplete injury (PABAK $=0.86-0.92)$. In other subgroups, agreement ranged from moderate to substantial (PABAK $=0.41-0.73$ ). SCl-specific fracture thresholds (Eser versus Garland) showed poor agreement (PABAK $\leqslant 0$ ).

Conclusion: Fracture risk estimates among individuals with $\mathrm{SCl}$ vary substantially with the risk assessment tool. Use of SCl-specific risk factors to identify patients with high fracture risk is recommended until a validated $\mathrm{SCl}$-specific tool for predicting fracture risk is developed.

Spinal Cord (2017) 55, 985-993; doi:10.1038/sc.2017.65; published online 13 June 2017

\section{INTRODUCTION}

Altered bone metabolism is a consequence of spinal cord injury (SCI). The early post-injury period is characterized by increased osteoclast activity, transient hypercalcemia and excessive renal calcium excretion. ${ }^{1}$ These metabolic changes, in addition to the unloading of the long bones and vertebrae that occurs with SCI, result in losses of bone mineral density (BMD) in bones below the neurological lesion of $\sim 3 \%$ per month for the first 12-18 months. The severity of BMD decline depends on the neurologic level of injury, injury severity (ASIA Impairment Scale (AIS)), duration of injury, age at injury, muscle density, presence and severity of spasticity and sex of the individual with SCI, among other factors. ${ }^{2,3}$ Some authors have reported that bone metabolism reaches a new steady state $\sim 2$ years post injury. ${ }^{3,4}$ However, BMD does not recover to pre-injury levels, and sublesional osteoporosis commonly develops. Sublesional osteoporosis is characterized by low BMD and micro-architectural deterioration, and it differs from post-menopausal osteoporosis in its anatomic distribution, severity of bone resorption and rapidity of progression following SCI. ${ }^{5}$
Today, there are treatments for sublesional osteoporosis available (for example, oral bisphosphonates). ${ }^{6-8}$ However, there are no consensus-based guidelines for the initiation of sublesional osteoporosis therapy. ${ }^{7}$ In the absence of such guidelines, an estimate of an individual's risk of a fragility fracture would be helpful in assisting clinicians to identify individual patients with an increased risk of fragility fracture who may benefit from pharmacotherapy to augment bone mass and education regarding fracture prevention. Nevertheless, currently available tools have not been validated for assessing fragility fracture risk among individuals with chronic SCI.

As a first step toward developing an SCI-specific fracture risk prediction tool, we examined the concordance between existing tools for fracture risk assessment in the general population, the Canadian Association of Radiologists and Osteoporosis Canada (CAROC) tool ${ }^{9}$ and the Canadian version of the World Health Organization Fracture Risk Assessment (Canadian FRAX) tool. ${ }^{10}$ CAROC and Canadian FRAX are the 'gold-standard' tools for predicting 10-year fragility fracture risk in Canada. They were designed for use in the older adult

\footnotetext{
${ }^{1}$ Department of Research, Neural Engineering and Therapeutics Team, Toronto Rehabilitation Institute-University Health Network, Toronto, Ontario, Canada; ${ }^{2}$ Department of Kinesiology, University of Waterloo, Waterloo, Ontario, Canada; ${ }^{3}$ Brain and Spinal Cord Rehabilitation Program, Toronto Rehabilitation Institute-University Health Network, Toronto, Ontario, Canada; ${ }^{4}$ Department of Medicine, McMaster University, Hamilton, Ontario, Canada; ${ }^{5}$ Department of Clinical Epidemiology and Biostatistics, McMaster University, Hamilton, Ontario, Canada and ${ }^{6}$ Division of Physiatry, Department of Medicine, University of Toronto, Toronto, Ontario, Canada

Correspondence: Dr T Cervinka, Department of Research, Neural Engineering and Therapeutics Team, Toronto Rehabilitation Institute-University Health Network, 520 Sutherland Dr, Toronto, Ontario, Canada M4G 3V9.

E-mail: tomas.cervinka@hotmail.com

Received 16 November 2016; revised 29 April 2017; accepted 2 May 2017; published online 13 June 2017
} 
population (post-menopausal women and men over age 50), and show $\sim 90 \%$ agreement in this group. ${ }^{11}$ However, their agreement in the SCI population has not been reported.

The CAROC tool has been validated for assessing 10-year risk of a fragility fracture in the Canadian older adult population, ${ }^{12}$ and it provides an assessment of fracture risk based on age, gender and femoral neck T-score derived from a dual X-ray absorptiometry (DXA) measurement of areal BMD (aBMD) (http://www.osteoporosis. $\mathrm{ca} /$ multimedia/FractureRiskTool/index.html\#/Home). CAROC also accounts for the increased risk of fracture associated with a history of fragility fractures or glucocorticoid use, but its use is restricted to adults aged 50 or older. Canadian FRAX is an online calculator that has been validated for use in the Canadian population (http://www.shef.ac.uk/FRAX/tool.aspx? country = 19). ${ }^{10}$ The FRAX tool accounts for the CAROC risk factors in addition to several other risk factors, including body mass index, current smoking, alcohol intake, parental hip fracture history and presence of rheumatoid arthritis. The FRAX tool assumes that all patients are at least 40 years of age.

Although the notion of a fracture threshold has fallen out of favor for use in the general older adult population, because of the strong relationship between declining aBMD and increasing fracture risk reported in several meta-analyses, ${ }^{13-16}$ the fracture threshold concept still has merit within the SCI population. ${ }^{17}$ Garland et al. ${ }^{18}$ have reported that a knee-region (that is, distal femoral or proximal tibial condyle) aBMD value yielded by the Hologic DXA densitometer correlates well with prevalent fractures in the SCI population. A regional aBMD below the fracture threshold of $0.78 \mathrm{~g} \mathrm{~cm}^{-2}$ or the fracture breakpoint of $0.49 \mathrm{~g} \mathrm{~cm}^{-2}$ (aBMD value below which the majority of fragility fractures occur) identifies individuals with an increased risk of prevalent fragility fracture. Eser et al. ${ }^{19}$ reported a trabecular volumetric BMD (vBMD, yielded by Stratec XCT scanner) fracture threshold of $72 \mathrm{mg} \mathrm{cm}^{-3}$ for the distal tibial epiphysis in an SCI population. SCI-specific threshold values for assigning fracture risk do not account for fracture risk factors beyond aBMD or vBMD, and they have not been prospectively validated for predicting incident fragility fractures among individuals with SCI. SCI-specific risk factors for lower-extremity fragility fractures that have been identified from bivariate analyses of predominantly retrospective data include history of fragility fracture, ${ }^{20}$ family history of fragility fracture, ${ }^{20}$ body mass index $<19,{ }^{18}$ duration of injury $\geqslant 10$ years, ${ }^{21}$ female sex, ${ }^{21,22}$ age at injury $<16$ years, ${ }^{23}$ motor complete injury, ${ }^{24}$ paraplegia, ${ }^{25}$ alcohol use $>5$ servings per $\mathrm{day}^{26}$ and use of specific medications including opioid analgesia, ${ }^{27}$ benzodiazepines ${ }^{28}$ or unfractionated heparin. ${ }^{27,28}$ Of note, the latter four risk factors are modifiable and may be targets for reducing an individual's risk of fragility fracture after SCI. However, the relative importance of SCI-specific risk factors for fragility fracture prediction has not been established, and their prevalence as a group in the SCI population has not been reported. Notably, several of these risk factors are not considered in the CAROC or Canadian FRAX tools.

The overarching aim of this current study was to explore how sensitive fracture risk assessment tools are to the assessment method selected in individuals with chronic SCI. The specific objectives of this study are as follows: (1) to report the agreement between the CAROC and Canadian FRAX with and without use of aBMD in a cohort of chronic SCI participants; (2) to report the agreement between the Garland et al. and Eser et al. fracture threshold criteria in a cohort of chronic SCI participants; and (3) to report the prevalence of fragility fracture risk factors and SCI-specific fragility fracture risk factors in this cohort. The results of this work will elucidate the sensitivity of fracture risk assessment in individuals with SCI to the tool selected, and will inform SCI-specific fragility fracture risk assessment.

\section{PATIENTS AND METHODS}

\section{Setting and study participants}

Baseline data from a prospective cohort study of bone quality in adults with chronic SCI was used for cross-sectional analyses. Adults, at least 18 years of age, with chronic traumatic SCI (C2-T12, AIS A-D, duration of injury $>2$ years) were recruited from outpatient physiatry clinics at tertiary SCI rehabilitation hospitals in the Canadian provinces of Ontario $(n=70)$ and Québec $(n=20)$. The processes for recruitment, screening, consent and retention of subjects are described elsewhere. ${ }^{29}$

Individuals exposed to bisphosphonates were eligible for the study. Individuals who reported a current or prior condition other than SCI known to influence bone metabolism were excluded from the study. Participants treated for vitamin D deficiency, hypogonadism or hypothyroidism were not excluded. Participants $>122.5 \mathrm{~kg}$ in weight and pregnant women or pre-menopausal women planning to become pregnant were excluded. The study was approved by the local Research Ethics Boards at each site (Toronto Rehabilitation Institute, University of Waterloo, Institute for Disability Rehabilitation in Physics of Quebec, Centre hospitalier de l'Université Laval). We certify that all applicable institutional and governmental regulations concerning the ethical use of human volunteers were followed up during the course of this cohort study.

\section{Procedures}

Medical history, sociodemographic and injury characteristics were collected from each participant. These data were used to describe the cohort and estimate the prevalence of known osteoporosis or fracture risk factors, including demographic data (sex, age, weight and height); injury characteristics (age at injury, duration of injury, neurological level of injury and AIS Category); medical history (reported history of fragility fracture, parental history of hip fracture, alcohol use, tobacco use, type II diabetes mellitus, rheumatoid arthritis, ankylosing spondylitis, hypogonadism, hyperparathyroidism, vitamin D deficiency, chronic liver or kidney disease, multiple myeloma, leukemia, chronic obstructive pulmonary disease or malabsorption syndromes such as Crohn's disease, ulcerative colitis, celiac disease or history of bariatric surgery) and bisphosphonate exposure (defined as $80 \%$ reported adherence for $\geqslant 6$ months) or medications known to modify bone mass or increase fracture risk (for example, unfractionated heparin, excessive thyroid hormone replacement, androgen deprivation therapy, opioids or benzodiazepines). History of fracture was ascertained using self-report and medical record verification of fracture location. Fragility fractures were determined as fractures that occurred spontaneously or after minor trauma such as a fall from sitting or standing height. ${ }^{30}$ Fragility fractures were identified at the following anatomic sites: radius, ulna, humerus, rib, hip, femur, knee, tibia, fibula and ankle. Of note, we screened for clinical vertebral fractures, but no fragility fractures occurred in our cohort. Nose and toe regions' fractures were not considered fragility fractures.

A Hologic Discovery QDR 4500 (model A or W, depending on study site) DXA densitometer (Hologic Inc., Waltham, MA, USA) was used to acquire aBMD scans of the spine, left total hip, right distal femur and right proximal tibia regions for each participant. Participants with hardware implants or joint contractures had their contralateral limb scanned (right hip, $n=12$; left distal femur, $n=29$; left proximal tibia, $n=31)$. Of note, total hip scans of $3(3.3 \%)$ participants were not acquired due to bilateral hip hardware. Spine and total hip DXA scans were analyzed by an International Society of Clinical Densitometry-trained technologists using the manufacturer's software (the least significant change for spine and hip aBMD are $2.5 \%$ and $3.5 \%$, respectively ${ }^{31}$ ). The acquired aBMD T-score of the femoral neck and lumbar spine, and the aBMD T-score of the femoral neck were used as input into the CAROC and Canadian FRAX tools, respectively.

The technologist used a previously reported knee aBMD analysis protocol for the DXA distal femur and proximal tibia scans (least significant change for distal femur, $2 \%$ and for proximal tibia, 3\%). ${ }^{29}$ In brief, a polycarbonate positioning device, not recognized by the densitometer, maintains lowerextremity position during scan acquisition. The laser crosshairs are placed $5 \mathrm{~cm}$ 
Table 1 List of data elements included in the CAROC and Canadian FRAX screening tools

\begin{tabular}{|c|c|c|}
\hline & \multicolumn{2}{|c|}{ Screening tool } \\
\hline & CAROC & Canadian FRAX \\
\hline \multicolumn{3}{|l|}{ Bone mineral density data } \\
\hline Femoral neck aBMD T-score & $x$ & Optional \\
\hline Lumbar spine aBMD T-score & Optional & \\
\hline \multicolumn{3}{|l|}{ Demographic data } \\
\hline Age & $\mathrm{x}$ & $\mathrm{x}$ \\
\hline Gender & $\mathrm{x}$ & $\mathrm{x}$ \\
\hline Height & & $x$ \\
\hline Weight & & $\mathrm{x}$ \\
\hline \multicolumn{3}{|l|}{ Clinical risk factors } \\
\hline Prior fragility fracture & $x$ & $x$ \\
\hline Parental $\mathrm{Hx}$ of hip fracture & & $\mathrm{x}$ \\
\hline Glucocorticoid use ${ }^{a}$ & $x$ & $x$ \\
\hline Cause of secondary osteoporosis & & $x$ \\
\hline Rheumatoid arthritis & & $x$ \\
\hline \multicolumn{3}{|l|}{ Lifestyle risk factors } \\
\hline Current smoking & & $\mathrm{x}$ \\
\hline Alcohol use $\geqslant 3$ servings per day & & $x$ \\
\hline
\end{tabular}

Abbreviations: aBMD, areal bone mineral density; CAROC, Canadian Association of Radiologists and Osteoporosis Canada; FRAX, Fracture Risk Assessment Tool; Hx, history; srv, servings. aDefined as reported exposure equivalent to $7.5 \mathrm{mg}$ prednisone daily for 3 months (cumulative) during the preceding year.

'One serving is defined as $341 \mathrm{ml}$ of beer (standard Canadian longneck bottle), $120 \mathrm{ml}$ of wine or $30 \mathrm{ml}$ of hard liquor or spirits.

distal to the inferior border of the patella for the distal femur and $23 \mathrm{~cm}$ distal to the superior border of the patella for the proximal tibia. Total scan length is $24 \mathrm{~cm}$ for both the distal femur and proximal tibia. Scans are analyzed using the Hologic lumbar spine software. The distal femur and proximal tibia T-scores and $Z$-scores were obtained from a local research database valid for adults' age $18-70$ years.

An XCT-2000 peripheral quantitative computed tomography (pQCT) scanner (Stratec Medizintechnik, Pforzheim, Germany) was used to acquire vBMD data at the tibia $(n=70)$ for Ontario participants; no pQCT data was collected from Quebec participants $(n=20)$. The pQCT scanner generates a cross-sectional image based on 145 projection scans obtained using a narrow $\mathrm{X}$-ray fan beam. A trained technologist scanned the right tibia of each participant from the Ontario study sites, except in participants $(n=11)$ with contraindications to pQCT scanning, for whom the left tibia was scanned. The technologist identified the distal endplate of the tibia on a $30 \mathrm{~mm}$ coronal scout scan, and used this line as an anatomical reference. The technologist then imaged the distal tibia epiphysis using a $2.5 \mathrm{~mm}$ scan $(0.2 \mathrm{~mm}$ voxel size $)$ at $4 \%$ of the tibia length (defined as the distance between the medial border of the tibia plateau and the most distal point on the medial malleolus), measured proximally to the anatomical reference line. The technologist analyzed the pQCT scans using Stratec XCT-2000 software (version 6.0) to obtain the distal tibia trabecular vBMD for each participant (CALCBD mode, contour mode 3 , peel mode 2, outer threshold $130 \mathrm{mg} \mathrm{cm}^{-3}$, inner threshold $400 \mathrm{mg} \mathrm{cm}^{-3}$ ).

\section{Fracture risk assessment tools}

We determined the 10-year risk of fragility fracture for each participant using the CAROC and Canadian FRAX tools. ${ }^{9,10}$ Table 1 lists the data elements included in the CAROC and Canadian FRAX tools. The Canadian FRAX can be used with and without aBMD; therefore, for clarity, we use the terms FRAX with aBMD and FRAX without aBMD, as appropriate. Both fracture risk assessment tools specify the lowest age for which a valid assessment can be performed- 50 years for CAROC and 40 years for Canadian FRAX.
The Canadian FRAX calculator automatically assesses individuals younger than 40 years as if they were 40 years of age, and it warns the user about the potential inaccuracy of its risk prediction for the age group. The CAROC calculator does not provide data for individuals $<50$ years of age. Therefore, we first determined the 10-year fragility fracture risk using the published CAROC tool for all cohort members 50 years of age or older, assigning a risk assessment of 'not applicable' to participants younger than 50 years. We then repeated the CAROC risk assignment, inserting age 50 years for all participants below age 50 years. We refer to this second analysis as the 'Modified Age CAROC' assessment. Although it is not recommended to assess patients below age 50 years due to the lack of absolute risk assessment, ${ }^{32}$ our rationale for evaluating fracture risk in those younger than 50 years in this manner was that clinicians faced with a young patient for whom they are concerned about fracture risk, and are faced with equipoise regarding treatment, would likely make the same-age substitution to obtain some estimate of fracture risk. CAROC directly determines whether particular individuals are at low, moderate or high risk of fracture. FRAX provides a risk level in percentage; we categorized FRAX-based 10-year major osteoporotic fracture risk determined as low $(<10 \%)$, moderate $(10-20 \%)$ or high $(>20 \%)$ as recommended by Canadian Multicentre Osteoporosis Study Research Group. ${ }^{11}$ Of note, the FRAX tool assesses only individuals whose weight is $\leqslant 125 \mathrm{~kg}$. One individual in our cohort $(0.9 \%)$ exceeded this limit by $12.4 \mathrm{~kg}$. Nevertheless, we assessed his fracture risk as if he weighed $125 \mathrm{~kg}$. Further, parental history of hip fracture was known in 64/90 (71\%) participants. The remaining participants were assessed as having no history of parental hip fracture. Furthermore, the fracture risk determination by the CAROC tool can be adjusted by participant spine region T-score values. This value, however, was not available for 11 participants $(12 \%)$ due to regional hardware from prior open reduction internal fixation of the lower thoracic or lumbar spine region. Therefore, we decided to use T-score equals to 0 for their fracture risk evaluation. The rationale for this choice was that only T-scores below -2.5 would affect the CAROC femoral neck-based fracture risk determination (increase of the risk category). ${ }^{11}$ As only 2 of 90 participants $(2 \%)$ had very-low-lumbar spine region T-score values, it is highly unlikely that our choice would have a substantial effect on fracture risk determination in these participants.

Additionally, we determined whether the knee-region aBMD for each participant was above or below the fracture threshold $\left(0.78 \mathrm{~g} \mathrm{~cm}^{-2}\right)$ and breakpoint $\left(0.49 \mathrm{~g} \mathrm{~cm}^{-2}\right)$ proposed by Garland et al. ${ }^{18}$ and whether the distal tibial epiphysis trabecular vBMD for each participant was above or below the fracture threshold $\left(72 \mathrm{mg} \mathrm{cm}^{-3}\right)$ reported by Eser et al. ${ }^{19}$

\section{Statistical analyses}

We used descriptive statistics, specifically, the mean and s.d. for continuous variables, and count and percent for categorical variables, to report participant demographic and impairment characteristics, risk factor prevalence and the proportion of participants stratified to each risk category by each tool. The dependence of demographic and impairment characteristic, and risk factor prevalence on all subgroup stratifications (for example, pre- versus postmenopausal women and men $<50$ years versus men $\geqslant 50$ years) was assessed by the $\chi^{2}$-test with significance set at 0.05 level. We expressed the agreement between pairs of risk assessment tools using prevalence- and bias-adjusted kappa (PABAK) ordinal scale. The strength of agreement is expressed by the following descriptors: $\leqslant 0=$ poor, $0.01-0.20=$ slight, $0.21-0.40=$ fair, 0.41-0.60 = moderate, $\quad 0.61-0.80=$ substantial and $\quad 0.81-1=$ excellent. $^{33}$ Negative values for PABAK indicate inverse agreement between tools, that is, a propensity for the risk category assigned by tool A to be different than the category assigned by tool $\mathrm{B}$. Of note, PABAK was used to avoid incorrect results of standard Cohen's kappa in situations when agreement between assessed tools is rare for one risk category combination but not for another.

We conducted subgroup analyses of agreement between tools among individuals with motor complete (AIS A/B) versus motor incomplete (AIS C/D) SCI, because motor complete injury is an important SCI-specific risk factor for fragility fracture. ${ }^{24}$ Completeness of injury is derived from the ASIA Impairment Scale category. ${ }^{34}$ We also conducted subgroup analyses for pre-menopausal versus post-menopausal women and for men $<50$ years versus men $\geqslant 50$ years, to examine whether agreement between risk assessment 
Table 2 Subject characteristics at baseline and prevalence of $\mathrm{SCl}$-specific fragility fracture risk factors

\begin{tabular}{|c|c|c|c|c|c|c|}
\hline & Descriptor & $\begin{array}{c}\text { All subjects } \\
(\mathrm{n}=90)\end{array}$ & $\begin{array}{l}\text { Pre-menopausal } \\
\text { women }(\mathrm{n}=19)\end{array}$ & $\begin{array}{c}\text { Post-menopausal } \\
\text { women }(\mathrm{n}=8)\end{array}$ & $\begin{array}{c}\text { Men aged }<50 \text { yrs } \\
(\mathrm{n}=35)\end{array}$ & $\begin{array}{c}\text { Men aged } \geqslant 50 y r s \\
(n=28)\end{array}$ \\
\hline \multicolumn{7}{|l|}{ Demographic data } \\
\hline Males & $n(\%)$ & $64(71)$ & $0(0)$ & $0(0)$ & 37 (100) & $27(100)$ \\
\hline Age (years) & Mean \pm s.d. & $48 \pm 12$ & $39 \pm 9$ & $61 \pm 8$ & $40 \pm 7$ & $59 \pm 7$ \\
\hline Height (m) & Mean \pm s.d. & $1.75 \pm 0.10$ & $1.68 \pm 0.10$ & $1.65 \pm 0.06$ & $1.79 \pm 0.07$ & $1.76 \pm 0.10$ \\
\hline Weight (kg) & Mean \pm s.d. & $78.8 \pm 18.3$ & $67.8 \pm 21.5$ & $72.4 \pm 16.2$ & $79.5 \pm 15.9$ & $86.8 \pm 16.6$ \\
\hline \multicolumn{7}{|l|}{ Injury data } \\
\hline Age at $\mathrm{SCl}$ (years) & Mean \pm s.d. & $33 \pm 14$ & $25 \pm 10$ & $42 \pm 16$ & $27 \pm 9^{a}$ & $42 \pm 15^{a}$ \\
\hline Age at injury $<16$ yrs. $^{b}$ & $n(\%)$ & $2(2)$ & $1(6)$ & $0(0)$ & $1(3)$ & $0(0)$ \\
\hline Duration of injury (years) & Mean \pm s.d. & $15 \pm 10$ & $15 \pm 9$ & $19 \pm 10$ & $13 \pm 8$ & $17 \pm 12$ \\
\hline Duration of injury $\geqslant 10 \mathrm{yrs}^{\mathrm{b}}$ & $n(\%)$ & $60(67)$ & $12(71)$ & $7(78)$ & $23(62)$ & $18(67)$ \\
\hline Paraplegia $^{\mathrm{b}}$ & $n(\%)$ & $43(48)$ & $10(59)$ & $4(44)$ & $19(51)$ & $10(37)$ \\
\hline Motor complete injury (AIS A/B $)^{b}$ & $n(\%)$ & $60(67)$ & $14(82)$ & $4(44)$ & $26(70)$ & $16(59)$ \\
\hline \multicolumn{7}{|l|}{ Clinical data } \\
\hline Body mass index $<19^{b}$ & $n(\%)$ & $6(7)$ & $4(24)$ & $0(0)$ & $2(5)$ & $0(0)$ \\
\hline Current smoker & $n(\%)$ & $19(21)$ & $1(6)$ & $3(33)$ & $9(24)$ & $6(22)$ \\
\hline Reported alcohol use $\geqslant 3$ srv per day & $n(\%)^{c}$ & $2(2)$ & $0(0)$ & $0(0)$ & $2(5)$ & $0(0)$ \\
\hline Reported alcohol $>5$ srv per day ${ }^{b}$ & $n(\%)^{c}$ & $0(0)$ & $0(0)$ & $0(0)$ & $0(0)$ & $0(0)$ \\
\hline Reported $\mathrm{Hx}$ of fragility $\mathrm{Fx}^{\mathrm{b}}$ & $\#(n)^{\mathrm{d}}$ & $50(22)$ & $7(4)$ & $11(4)$ & $21(8)$ & $11(6)$ \\
\hline Reported family $\mathrm{Hx}$ of hip $\mathrm{Fx}^{\mathrm{b}}$ & $n(\%)^{\mathrm{e}}$ & $8(13)$ & $0(0)$ & $0(0)$ & $4(11)$ & $4(15)$ \\
\hline Reported bisphosphonate use & $n(\%)$ & $53(59)$ & $8(47)$ & $8(89)$ & $20(54)$ & $17(63)$ \\
\hline Reported glucocorticoid use & $n(\%)^{f}$ & $0(0)$ & $0(0)$ & $0(0)$ & $0(0)$ & $0(0)$ \\
\hline Reported opioid analgesia use $\mathrm{b}^{\mathrm{b}}$ & $\#(n)^{\mathrm{g}, \mathrm{h}}$ & $29(21)$ & $2(2)$ & $8(4)$ & $12(10)$ & $9(6)$ \\
\hline Reported benzodiazepine use ${ }^{b}$ & $n(\%)$ & $21(23)$ & $2(12)$ & $1(11)$ & $11(30)$ & $7(26)$ \\
\hline Reported heparin use ${ }^{b}$ & $n(\%)$ & $2(2)$ & $0(0)$ & $1(11)$ & $0(0)$ & $1(4)$ \\
\hline \multicolumn{7}{|l|}{ Bone quality data } \\
\hline Lumbar spine T-score & Mean \pm s.d. & $0.0 \pm 1.8$ & $0.8 \pm 2.5$ & $0.3 \pm 1.9$ & $-0.5 \pm 1.5$ & $0.2 \pm 1.5$ \\
\hline Femoral neck T-score & Mean \pm s.d. & $-2.0 \pm 1.1$ & $-1.4 \pm 1.3$ & $-2.0 \pm 1.5$ & $-2.2 \pm 1.0$ & $-2.1 \pm 1.0$ \\
\hline Distal femur aBMD $\left(\mathrm{g} \mathrm{cm}^{-2}\right)$ & Mean \pm s.d. & $0.616 \pm 0.194$ & $0.569 \pm 0.211$ & $0.564 \pm 0.267$ & $0.605 \pm 0.164$ & $0.678 \pm 0.192$ \\
\hline Proximal tibia aBMD $\left(\mathrm{g} \mathrm{cm}^{-2}\right)$ & Mean \pm s.d. & $0.504 \pm 0.156$ & $0.482 \pm 0.133$ & $0.484 \pm 0.212$ & $0.518 \pm 0.139$ & $0.506 \pm 0.174$ \\
\hline Distal tibia vBMD $\left(\mathrm{mg} \mathrm{cm}^{-3}\right)$ & Mean \pm s.d. & $134.4 \pm 55.7$ & $110.9 \pm 38.1$ & $125.7 \pm 69.6$ & $131.1 \pm 74.3$ & $156.7 \pm 83.6$ \\
\hline \multicolumn{7}{|c|}{ 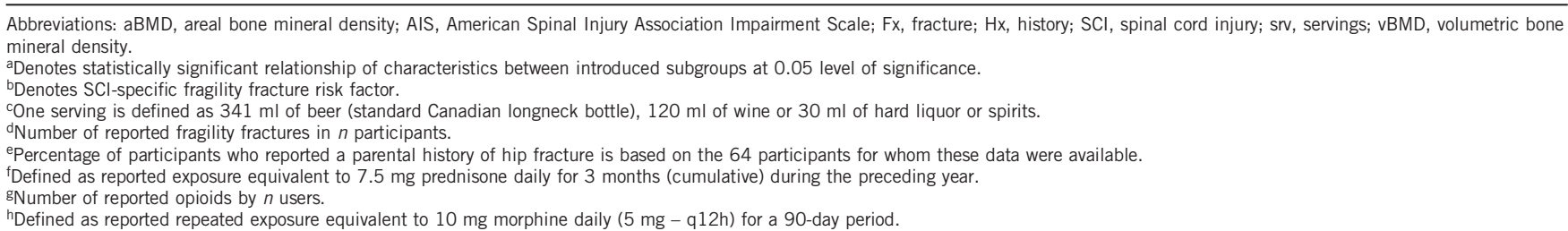 } \\
\hline
\end{tabular}

tools varied with menopausal status among women or with age among men. All analyses were performed using the R3.3.1 software (R Foundation for Statistical Computing, Vienna, Austria) for Windows.

\section{RESULTS}

Ninety participants consented to participate, of which the majority (71\%) were males with motor complete injuries (67\%). Approximately half of the cohort had paraplegia $(48 \%)$ versus tetraplegia (Table 2). The mean age of the motor complete group was 45 years, whereas the mean age of the motor incomplete group was 53 years. More than half the cohort reported bisphosphonate exposure (59\%). The most prevalent FRAX-derived risk factors for fracture among the cohort were reported as history of fragility fracture (25\%), current smoker $(21 \%)$ and presence of a condition associated with secondary osteoporosis, namely SCI (100\%) (Table 2). The prevalence of other risk factors included in FRAX was $<20 \%$. Many participants reported use of opioid analgesia (23\%) or benzodiazepines (23\%), or both. Heparin use was infrequent (2\%).

With respect to SCI-specific fracture risk factors, the most prevalent risk factors were paraplegia (48\%), motor complete injury (67\%) and duration of injury $\geqslant 10$ years $(67 \%)$. The motor complete (AIS A/B) subgroup exhibited a high prevalence of many SCI-specific risk factors for fragility fracture, including duration of injury $\geqslant 10$ years $(78 \%)$, motor complete injury $(100 \%)$, paraplegia $(50 \%)$, prior fragility fracture $(32 \%)$ and use of benzodiazepines $(30 \%)$ or opioids $(23 \%)$. The motor incomplete group (AIS C-D) had a high prevalence of paraplegia $(43 \%)$, opioid use $(23 \%)$ or benzodiazepine use $(10 \%)$, prior fragility fracture $(10 \%)$ and duration of injury $\geqslant 10$ years $(43 \%)$. Pre-menopausal women had a high prevalence of motor complete injury $(82 \%)$, paraplegia $(59 \%)$ or duration of injury $\geqslant 10$ years (71\%). Among men, the prevalence of SCI-specific risk factors was similar for both the younger and older subgroups. 
Table 3 Proportion of subjects stratified into 10-year fragility fracture risk categories, by tool

All participants in cohort

$$
\text { All subjects }(\mathrm{n}=90)
$$

Tool

Low Mod. High NA

\section{CAROC}

$\begin{array}{llll}0.21 & 0.11 & 0.09 & 0.59\end{array}$

Modified Age CAROC ${ }^{b}$

$\begin{array}{llll}0.52 & 0.28 & 0.17 & 0.03\end{array}$

$\begin{array}{llllll}\text { Canadian FRAX with aBMD } & 0.77 & 0.14 & 0.06 & 0.03\end{array}$

$\begin{array}{lllll}\text { Canadian FRAX without aBMD } & 0.89 & 0.10 & 0.01 & 0.00\end{array}$

All participants by SCl type

AIS A/B $(n=60)$

AIS C/D $(n=30)$

Tool

Low Mod. High NA Low Mod. High NA

CAROC

Modified Age CAROC ${ }^{b}$

$\begin{array}{llllllll}0.13 & 0.08 & 0.12 & 0.67 & 0.37 & 0.17 & 0.03 & 0.43\end{array}$

Canadian FRAX with aBMD

$\begin{array}{llllllll}0.43 & 0.28 & 0.23 & 0.05 & 0.70 & 0.27 & 0.03 & 0.00\end{array}$

$\begin{array}{lllllllll}\text { Canadian FRAX without aBMD } & 0.90 & 0.10 & 0.00 & 0.00 & 0.87 & 0.10 & 0.03 & 0.00\end{array}$

Female participants by menopausal status

Pre-menopausal women Post-menopausal women $(n=17)$ $(n=9)$

Tool

Low Mod. High NA Low Mod. High NA

CAROC

$\begin{array}{llllllll}0.12 & 0.00 & 0.00 & 0.88 & 0.22 & 0.44 & 0.22 & 0.11\end{array}$

Modified Age CAROC ${ }^{b}$

$\begin{array}{llllllll}0.65 & 0.18 & 0.12 & 0.06 & 0.22 & 0.44 & 0.22 & 0.11\end{array}$

$\begin{array}{lllllllll}\text { Canadian FRAX with aBMD } & 0.94 & 0.00 & 0.00 & 0.06 & 0.33 & 0.33 & 0.22 & 0.11\end{array}$

$\begin{array}{lllllllll}\text { Canadian FRAX without aBMD } & 1.00 & 0.00 & 0.00 & 0.00 & 0.44 & 0.44 & 0.11 & 0.00\end{array}$

Male participants by age

Men aged $<50$ years Men aged $<50$ years

$$
(n=37)
$$$$
(n=27)
$$

Tool

Low Mod. High NA Low Mod. High NA

CAROC

Modified Age CAROC ${ }^{b}$

$\begin{array}{llllllll}0.00 & 0.00 & 0.00 & 1.00 & 0.56 & 0.22 & 0.22 & 0.00\end{array}$

Canadian FRAX with aBMD

$\begin{array}{lllllllll}0.51 & 0.32 & 0.14 & 0.03 & 0.56 & 0.22 & 0.22 & 0.00\end{array}$

Abbreviations: aBMD, areal bone mineral density; AIS, ASIA Impairment Scale; CAROC

Canadian Association of Radiologists and Osteoporosis Canada; FRAX, Fracture Risk Assessment

Tool; SCl, spinal cord injury.

NA indicates that no risk stratification was assigned by the tool.

b2010 CAROC criteria applied to all participants, assuming that all participants are at least 50 years old.

Generally, the proportion of individuals assigned to a 'high-risk' category was greater for the CAROC tool than for the Canadian FRAX tool (both with and without aBMD) in the overall cohort and subpopulations with exception of the motor incomplete (AIS C/D) subgroup. However, 59\% of all participants could not be assigned to a risk category by CAROC because they were under 50 years of age (Table 3).

Ninety-four percent of participants had a knee-region aBMD below the Garland et al. fracture threshold of $0.78 \mathrm{~g} \mathrm{~cm}^{-2}$ (Table 4). Fifty-four percent of the cohort also exhibited a knee-region aBMD below the fracture breakpoint of $0.49 \mathrm{~g} \mathrm{~cm}^{-2}$ determined by Garland et al. In contrast, $6 \%$ of the cohort had a distal tibia trabecular vBMD less than the Eser et al. fracture threshold of $72 \mathrm{mg} \mathrm{cm}^{-3}$.
Fracture risk stratification using the Canadian FRAX tools with and without aBMD exhibited substantial agreement in the overall cohort $(\mathrm{PABAK}=0.78,95 \%$ confidence interval $(\mathrm{CI})$ : 0.69-0.87). The excellent agreement was yielded among younger individuals (pre-menopausal women and men aged $<50$ years) and individuals with motor incomplete injury (PABAK $=0.86-0.92)$. However, these tools yielded only substantial agreement in individuals with motor complete injury (PABAK $=0.73,95 \% \mathrm{CI}: 0.62,0.84)$ and moderate agreement when used for post-menopausal women with SCI $(\mathrm{PABAK}=0.41,95 \% \mathrm{CI}: 0.12,0.69)$, respectively.

Among the participants who were assigned a risk category by CAROC, the agreement between the CAROC and Canadian FRAX tools with (PABAK $=0.08,95 \% \mathrm{CI}$ : $-0.01,0.17)$ and without aBMD (PABAK $=-0.07,95 \%$ CI: $-0.16,0.02$ ) was slight and poor, respectively, just failing statistical significance (Table 5). CAROC and Canadian FRAX with aBMD yielded a moderate agreement only for the post-menopausal participants with SCI (PABAK $=0.56,95 \% \mathrm{CI}$ : $0.27,0.84$ ) and men older than 50 years (PABAK $=0.51,95 \%$ CI: 0.34 , 0.67). Fracture risk stratifications using the Modified Age CAROC (where those younger than 50 were assumed to be 50 years of age) and Canadian FRAX tool with aBMD exhibited substantial agreement among individuals with motor incomplete injury $(\mathrm{PABAK}=0.73$, 95\% CI: 0.58, 0.89). Nevertheless, across all age groups and genders, the agreement of these tools was only moderate (PABAK $=0.5-0.56$ ). The Modified Age CAROC and Canadian FRAX tool without aBMD exhibited only moderate agreement in individuals with motor incomplete injury (PABAK $=0.6,95 \% \mathrm{CI}: 0.45,0.76)$ and pre-menopausal women (PABAK $=0.45,95 \% \mathrm{CI}$ : $0.25,0.66)$. In every subgroup, the Canadian FRAX tool (with and without aBMD) assigned a large proportion of the group to the low-risk stratum, whereas the Modified Age CAROC tool yielded a more even distribution of participants across the low-, moderate- and high-risk strata. The Garland and Eser fracture threshold criteria had poor agreement in the study population (PABAK $=-0.35,95 \% \mathrm{CI}:-0.45$, -0.25 ) or any of its subgroups (PABAK $\leqslant 0$ for all subgroups).

\section{DISCUSSION}

Despite the excellent agreement between the CAROC and Canadian FRAX tools in the general population, agreement between fracture risk assessment tools is poor when applied to individuals with SCI. Risk stratification was sensitive to tool selection, as observed in the cohort as a whole, and among the subgroups of individuals who were motor complete (AIS A/B), motor incomplete (AIS C/D), pre-menopausal women and men aged $<50$ years. The Canadian FRAX tool with and without aBMD showed excellent agreement for younger individuals (men aged $<50$ years and pre-menopausal women) and individuals with motor incomplete injury. These data imply that aBMD is a relevant bone quality indicator among individuals with SCI for assessment of fragility fracture risk. When comparing the CAROC and FRAX with aBMD tools, the only subgroups for which risk assessment was not sensitive to tool selection were post-menopausal women and men aged $\geqslant 50$ years. This result is not surprising, because the CAROC and FRAX tools were designed for this population, albeit for neurologically intact individuals. The Modified Age CAROC assessment, in which all individuals who were aged $<50$ years were assessed for fracture risk as though they were 50 years of age, generally showed fair to moderate agreement with the Canadian FRAX tool. Therefore, there may be a need for guidance on the preferred fracture risk assessment in pre-menopausal women and in men with low bone mass, particularly in instances, like SCI, where the risk factors for fracture are unique from the general population. 
Table 4 Proportion of subjects with BMD below fracture threshold or breakpoint

\begin{tabular}{|c|c|c|c|c|}
\hline \multicolumn{5}{|c|}{ All participants in cohort } \\
\hline \multirow[b]{2}{*}{ Tool } & \multicolumn{4}{|c|}{ All subjects $\left(n_{\text {Garland }}=88, n_{\text {Eser }}=62\right)$} \\
\hline & $\mathrm{BMD}<\mathrm{FT}$ & $\mathrm{BMD}<\mathrm{BP}$ & & \\
\hline Garland et al. ${ }^{a}$ & 0.94 & 0.54 & & \\
\hline Eser et $a l^{b}$ & 0.06 & NA & & \\
\hline \multicolumn{5}{|c|}{ All participants by SCl type } \\
\hline & \multicolumn{2}{|c|}{$\begin{array}{c}\text { AIS A/B }\left(n_{\text {Garland }}=59,\right. \\
\left.n_{\text {Eser }}=37\right)\end{array}$} & \multicolumn{2}{|c|}{$\begin{array}{c}\text { AIS C/D }\left(n_{\text {Garland }}=29,\right. \\
\left.n_{\text {Eser }}=25\right)\end{array}$} \\
\hline Tool & $\mathrm{BMD}<\mathrm{FT}$ & $\mathrm{BMD}<\mathrm{BP}$ & $\mathrm{BMD}<\mathrm{FT}$ & $\mathrm{BMD}<\mathrm{BP}$ \\
\hline Garland et al. ${ }^{a}$ & 0.98 & 0.68 & 0.86 & 0.24 \\
\hline Eser et al. ${ }^{\mathrm{b}}$ & 0.11 & NA & 0.00 & NA \\
\hline
\end{tabular}

Female participants by menopausal status

\begin{tabular}{lccccc} 
& $\begin{array}{c}\text { Pre-menopausal women } \\
\left(n_{\text {Garland }}=15, n_{\text {Eser }}=12\right)\end{array}$ & & $\begin{array}{c}\text { Post-menopausal women } \\
\left(n_{\text {Garland }}=9, n_{\text {Eser }}=7\right)\end{array}$ \\
\cline { 2 - 3 } Tool & $\mathrm{BMD}<\mathrm{FT}$ & $\mathrm{BMD}<\mathrm{BP}$ & & $\mathrm{BMD}<\mathrm{FT}$ & $\mathrm{BMD}<\mathrm{BP}$ \\
\hline Garland et al. ${ }^{\mathrm{a}}$ & 1.00 & 0.69 & & 0.89 & 0.67 \\
Eser et al. & 0.08 & $\mathrm{NA}$ & & 0.29 & $\mathrm{NA}$
\end{tabular}

Male participants by age

\begin{tabular}{lccccc} 
& $\begin{array}{c}\text { Men aged }<50 \text { years } \\
\left(n_{\text {Garland }}=37, n_{\text {Eser }}=24\right)\end{array}$ & & \multicolumn{2}{c}{$\begin{array}{c}\text { Men aged } \geqslant 50 \text { years } \\
\left(n_{\text {Garland }}=27, n_{\text {Eser }}=19\right)\end{array}$} \\
\cline { 2 - 3 } Tool & BMD $<\mathrm{FT}$ & $\mathrm{BMD}<\mathrm{BP}$ & & $\mathrm{BMD}<\mathrm{FT}$ & $\mathrm{BMD}<\mathrm{BP}$ \\
\hline Garland et al. ${ }^{\mathrm{a}}$ & 0.97 & 0.49 & & 0.89 & 0.48 \\
Eser et al. & 0.00 & $\mathrm{NA}$ & 0.05 & $\mathrm{NA}$
\end{tabular}

Abbreviations: AIS, ASIA Impairment Scale; BMD, bone mineral density; BP, breakpoint; $\mathrm{FT}$, fracture threshold; $\mathrm{NA}$, not applicable; $\mathrm{SCl}$, spinal cord injury.

aKnee-region $\mathrm{aBMD}<$ fracture threshold of $0.78 \mathrm{~g} \mathrm{~cm}^{-2}$, fracture breakpoint of $0.49 \mathrm{~g} \mathrm{~cm}^{-2}$.

bistal tibial epiphysis trabecular $v B M D<$ fracture threshold of $72 \mathrm{mg} \mathrm{cm}^{-3}$.

\section{FRAX with and without aBMD}

There are discrepancies when comparing fracture risk stratifications by Canadian FRAX with and without aBMD in the overall cohort and post-menopausal women. Our results showed $\sim 80 \%$ agreement between the Canadian FRAX with and without aBMD for the entire cohort, with reclassification of $20 \%$ of the cohort when aBMD is added. In contrast, there was only $56 \%$ agreement among post-menopausal women (data not shown). The observed agreement between these tools among SCI cohort members as a whole is consistent with the study published by Leslie et al., ${ }^{12}$ describing fracture risk agreement using FRAX with and without aBMD in the general population in Manitoba. Leslie et al. reported that $\sim 22 \%$ of the general population were reclassified when aBMD was considered in Canadian FRAX evaluation, the moderate-risk category being reclassified most frequently $(\sim 10 \%)$.

\section{CAROC and FRAX}

Lack of concordance of fracture risk stratification (low, moderate or high) is also observed between the CAROC and FRAX tools. Although 95\% CI suggested nonsignificant poor to slight agreement between these tools, the nonsignificance is likely due to a limited population size in our cohort as limits of $95 \%$ CI are very close to zero (Table 5). Therefore, one can presume that with a larger population size, the differences between CAROC and FRAX tools will become significant.

Several factors may account for the surprisingly low observed agreement between CAROC (or Modified Age CAROC) and Canadian FRAX (both with and without aBMD). First, the SCI population is much younger than the general population for whom these tools were designed, and have, on average, aBMD T-scores that are much lower than those of their age- and gender-matched peers within the general population. Notably, the CAROC tool could not be applied to $58 \%$ of the cohort because of the relatively young age of individuals with SCI. Second, several risk factors (for example, alcohol intake, smoking and secondary osteoporosis) are included in FRAX but not in CAROC and are more prevalent in the SCI population than in the general population. For example, FRAX defines a history of fragility fractures as any spontaneous or low-trauma fracture, whereas CAROC considers only vertebral and hip fractures, and the number of fragility fractures occurring in the forearm, humerus and proximal femur after age 40 years to be associated with an increased risk of fracture. ${ }^{12}$ Six percent of healthy men aged 50-90 years and 13\% of healthy women aged 50-90 years ${ }^{35}$ report a history of fragility fractures (FRAX definition), compared to $24 \%(n=22)$ of our cohort. However, only $16(18 \%)$ individuals with SCI in our cohort report a history of fragility fractures that meets the CAROC definition. Thus, variability in the definition of fragility fracture likely explains the discordance in fracture risk observed between CAROC and FRAX.

\section{SCI-specific fracture thresholds}

Although SCI-specific fracture risk thresholds have been proposed, a secondary finding of this study was that there is poor agreement between the Garland et al. ${ }^{21}$ and Eser et al. ${ }^{19}$ fracture thresholds for individuals with SCI. In fact, the agreement between these tools was so low that any concordance was likely due to chance. The observed discordance between the Garland and Eser criteria is not surprising, as they use different imaging modalities (DXA and pQCT) and examine different anatomical regions. Moreover, the Eser approach uses a measure of exclusively trabecular bone, whereas the Garland approach uses a composite of trabecular and cortical bone, and does not completely remove bone size as a contributing factor to aBMD. In addition, the Garland fracture threshold and breakpoint were developed based on data from a heterogeneous group of males with SCI, whereas the Eser threshold was based on a cohort comprised predominantly of men $(90 \%)$ with complete paraplegia (70\%), who often have low BMD as a result of their motor complete injury. ${ }^{3}$ On the other hand, both approaches assess BMD risk in the lower extremity where fractures most often occur. Our work published by Lala et al. ${ }^{29}$ has shown that low BMD using either DXA of the distal femur or proximal tibia, or pQCT of the distal tibia, was associated with prevalent fractures. Therefore, it could be expected that those at risk for lower-extremity fragility fracture, should have low BMD using either modality DXA or pQCT. Nevertheless, it is possible that the Eser's fracture threshold needs to be higher; our work suggested that all individuals with a prevalent fracture had a tibia trabecular vBMD of $87.7 \pm 25.2 \mathrm{mg} \mathrm{cm}^{-3.29}$ If the concept of fracture threshold is to be used, research validating the most appropriate anatomical site to assess the threshold level, and specifying the image acquisition and analysis procedures for each threshold is needed. The observed discordance between the various fracture risk assessment methods highlights the fact that risk stratification is highly sensitive to tool selection, the clinical factors incorporated within the tool and the definition(s) of prior fracture. 
Table 5 Agreement between risk stratification tools-estimated PABAK (95\% confidence interval)

All subjects in cohort

Tools

All subjects

\begin{tabular}{|c|c|c|c|}
\hline Canadian FRAX with & CAROC & Modified Age C & Eser et al. \\
\hline$a B M D$ & & $A R O C$ & \\
\hline
\end{tabular}

\begin{tabular}{|c|c|c|c|c|}
\hline $\begin{array}{l}\text { CAROC } \\
\text { Modified Age }\end{array}$ & $\begin{array}{c}0.08(-0.01,0.17) \\
0.54(0.45,0.63)\end{array}$ & $0.26(0.17,0.35)$ & $0.26(0.17,0.35)$ & - \\
\hline $\begin{array}{l}\text { CAROC }^{\text {CAR }} \\
\text { Canadian } \\
\text { FRAX without } \\
\text { aBMD }\end{array}$ & $0.78(0.69,0.87)$ & $-0.07(-0.16,0.02)$ & $0.35(0.26,0.44)$ & - \\
\hline Garland et al. & - & - & - & $-0.35(-0.45,-0.25)$ \\
\hline
\end{tabular}

By SCl type

\begin{tabular}{|c|c|c|c|c|c|c|c|c|}
\hline \multirow[b]{2}{*}{ Tools } & \multicolumn{4}{|c|}{ AIS A/B } & \multicolumn{4}{|c|}{ AIS C/D } \\
\hline & $\begin{array}{l}\text { Canadian FRAX with } \\
\text { aBMD }\end{array}$ & CAROC & Modified Age CAROC ${ }^{a}$ & Eser et al. & $\begin{array}{l}\text { Canadian FRAX } \\
\text { with } \mathrm{aBMD}\end{array}$ & CAROC & $\begin{array}{l}\text { Modified Age } \\
\text { CAROC }^{\mathrm{a}}\end{array}$ & Eser et al. \\
\hline CAROC & $-0.04(-0.15,0.07)$ & - & $0.20(0.09,0.31)$ & - & $0.29(0.13,0.44)$ & - & $0.42(0.27,0.58)$ & - \\
\hline Modified Age & $0.40(0.29,0.51)$ & $0.20(0.09,0.31)$ & - & - & $0.73(0.58,0.89)$ & $0.42(0.27,0.58)$ & - & - \\
\hline Canadian & $0.73(0.62,0.84)$ & $-0.20(-0.31,-0.09)$ & $0.18(0.07,0.29)$ & - & $0.87(0.71,1.00)$ & $0.16(0.00,0.31)$ & $0.60(0.45,0.76)$ & - \\
\hline
\end{tabular}

aBMD

Garland et al.

Female participants by age

Pre-menopausal women

Post-menopausal women

\begin{tabular}{|c|c|c|c|c|c|c|c|c|}
\hline Tools & $\begin{array}{l}\text { Canadian FRAX with } \\
\text { aBMD }\end{array}$ & CAROC & Modified Age CAROCa & Eser et al. & $\begin{array}{l}\text { Canadian FRAX } \\
\text { with aBMD }\end{array}$ & CAROC & $\begin{array}{l}\text { Modified Age } \\
\text { CAROC }^{\mathrm{a}}\end{array}$ & Eser et al. \\
\hline $\begin{array}{l}\text { CAROC } \\
\text { Modified Age } \\
\text { CAROC }\end{array}$ & $\begin{array}{c}-0.10(-0.30,0.11) \\
0.53(0.32,0.74)\end{array}$ & $-0.02(-\overline{0} .23,0.19)$ & $-0.02(-0.23,0.19)$ & - & $\begin{array}{l}0.56(0.27,0.84) \\
0.56(0.27,0.84)\end{array}$ & $1.00(0 . \overline{72}, 1.00)$ & $\begin{array}{c}1.00(0.72,1.00) \\
-\end{array}$ & - \\
\hline $\begin{array}{l}\text { Canadian } \\
\text { FRAX without } \\
\text { aBMD }\end{array}$ & $0.92(0.72,1.00)$ & $-0.18(-0.38,0.03)$ & $0.45(0.25,0.66)$ & - & $0.41(0.12,0.69)$ & $-0.04(-0.32,0.25)$ & $\begin{array}{c}-0.04(-0.32 \\
0.25)\end{array}$ & - \\
\hline arland et al. & - & - & - & $-0.32(-0.55,-0.10)$ & - & - & - & $0.00(-0.31,0.31)$ \\
\hline
\end{tabular}

Male participants by age

Men aged $<50$ years

Men aged $\geqslant 50$ years

\begin{tabular}{|c|c|c|c|c|c|c|c|c|}
\hline Tools & $\begin{array}{l}\text { Canadian FRAX with } \\
\text { aBMD }\end{array}$ & CAROC & Modified Age CAROCa & Eser et al. & $\begin{array}{l}\text { Canadian FRAX } \\
\text { with aBMD }\end{array}$ & CAROC & $\begin{array}{l}\text { Modified Age } \\
\text { CAROC }^{\mathrm{a}}\end{array}$ & Eser et al. \\
\hline AROC & $\begin{array}{c}-0.30(-0.44,-0.16) \\
0.50(0.36,0.64)\end{array}$ & $-0.30(-\overline{0.44},-0.16)$ & $-0.30(-0.44,-0.16)$ & - & $\begin{array}{l}0.51(0.34,0.67) \\
0.51(0.34,0.67)\end{array}$ & $1.00(\overline{.84}, 1.00)$ & $\begin{array}{c}1.00(0.84,1.00) \\
-\end{array}$ & - \\
\hline $\begin{array}{l}\text { Canadian } \\
\text { FRAX without } \\
\text { aBMD }\end{array}$ & $0.86(0.72,1.00)$ & $-0.33(-0.47,-0.19)$ & $0.35(0.21,0.49)$ & - & $0.70(0.54,0.87)$ & $0.31(0.15,0.47)$ & $0.31(0.15,0.47)$ & - \\
\hline rland et al. & - & - & - & $-0.46(-0.61,-0.31)$ & - & - & - & $-0.28(-0.46,-0.10)$ \\
\hline
\end{tabular}

Abbreviations: aBMD, areal bone mineral density; AIS, ASIA Impairment Scale; CAROC, Canadian Association of Radiologists and Osteoporosis Canada; FRAX, Fracture Risk Assessment Tool;

PABAK, prevalence- and bias-adjusted kappa; SCl, spinal cord injury.

a2010 CAROC criteria applied to all participants, assuming that all participants are at least 50 years old.

\section{SCI-specific risk factors}

Many people with SCI are $<40$ or 50 years of age, with a near-normal life expectancy who will live with a high risk of fracture for the balance of their lifetime. Therefore, there is a need for SCI-specific risk assessment paradigms to identify those individuals who might benefit from fracture prevention strategies. It would be prudent for any fracture risk assessment guidelines for individuals with SCI to consider the importance of SCI-specific and non-SCI-specific risk factors. This study has demonstrated that the prevalence of traditional osteoporosis risk factors was relatively high in the SCI cohort. For example, $25 \%$ of the cohort reported a prior fragility fracture, which is consistent with the rates of fragility fracture reported in the literature..$^{20,36,37}$ Notably, a number of SCI-specific risk factors were also common (that is, duration of injury $\geqslant 10$ years, paraplegia, motor complete injury, use of opioid analgesia and benzodiazepines). Opioid analgesia use was more frequent among participants with motor incomplete paraplegia (AIS A/B paraplegia $30 \%$ versus AIS C/D paraplegia $38 \%$ ), whereas benzodiazepine use was more frequent among participants with motor complete injuries, regardless of neurological level of injury (AIS A/B paraplegia $23 \%$, AIS A/B tetraplegia $37 \%$ ). The relatively high prevalence of opioid analgesia and benzodiazepine use in the study cohort is important in light of newly reported data on the adverse effect of these medications on BMD in $\mathrm{SCI}^{27,28}$ and fracture risk, ${ }^{38}$ and their link with falls. We cannot comment on the accuracy of any of these tools for fracture prediction using the data presented in this paper. Indeed, no prospective studies examining the sensitivity and specificity of fracture risk assessment tools have been published. However, we do note that the incidence of fragility fractures in SCI, estimated to be $25-46 \%,{ }^{20}$ is much higher than the 10 -year fracture projections that are suggested by the CAROC, Canadian FRAX and Eser's criteria. Conversely, the proportion of the population at risk is likely less than that suggested by the threshold proposed by Garland et al. Indeed, if the Garland criterion was applied, 94\% of our population would be identified as having a knee-region aBMD below the fracture threshold. 


\section{Limitations}

The limitations of this study include the self-reported nature of the medication use, tobacco and alcohol use data. Self-reported data are less accurate than more objective but time-consuming data collection methods such as chart abstraction. Also, pQCT scans were not available for all subjects. Reasons for incomplete pQCT included a limb girth, which exceeded the scanner gantry, contractures or severe spasticity limiting our ability to position participants for scan acquisition, or for those residing in Quebec. Participants with contractures or spasticity may have been more medically fragile than participants eligible for pQCT scanning; Eser's criteria may have under-reported the proportion of participants with a tibia vBMD below the fracture threshold. Further, our findings do not preclude the possibility that one of the available fracture risk assessment methods can be appropriately used to estimate fragility fracture risk in individuals with SCI, but the large variability in risk stratification for the cohort in general and among the various subgroups calls into question the accuracy of a single tool.

\section{CONCLUSIONS}

At this time, we do not recommend that clinicians rely solely upon the CAROC or Canadian FRAX tools for predicting fracture risk in people with SCI, as these tools may underestimate fracture risk by not assessing important SCI-specific risk factors. Similarly, the Garland and Eser fracture threshold and fracture breakpoint values may overestimate and underestimate the number of people at risk of fracture, respectively. Clinicians should make patients with SCI aware of their SCI-specific risk factors for lower-extremity fragility fracture and make a concerted effort to address modifiable fracture risk factors. Addressing modifiable risk factors via lifestyle choices such as abstaining from smoking, restricting caffeine and alcohol intake are advised. Clinicians should assess hip- or knee-region BMD T-scores or $Z$-scores in accordance with recommendations by the International Society for Clinical Densitometry, and record the number of SCI-specific risk factors for fracture. The combined results of these screening tools should identify patients with a moderate to high fracture risk for whom risk factor modification is indicated and therapy should be considered. In light of recent reports of the increased risk of fragility fracture posed by opioid, ${ }^{27,38}$ benzodiazepine $e^{28}$ and heparin therapy ${ }^{27,28}$ in SCI individuals, clinicians should also re-visit their patients' use of these medications to ensure that the benefit of these therapies outweighs the associated increase in fracture risk. We trust that this paper will foster discussion in the SCI community regarding the optimal processes for identification and mitigation of fragility fracture risk among individuals with chronic SCI.

\section{DATA ARCHIVING}

There were no data to deposit.

\section{CONFLICT OF INTEREST}

LG has received funding from Merck Canada Inc., and is a co-investigator on a project funded by Amgen Inc. JDA reports grants and personal fees from Amgen Inc., grants and personal fees from Eli Lilly, grants and personal fees from Merck Canada Inc., grants from Actavis, personal fees from Agnovos, outside the submitted work. BCC reports consulting fees from the Rick Hansen Institute. The remaining authors declare no conflict of interest.

\section{ACKNOWLEDGEMENTS}

We acknowledge the support of the Ontario Neurotrauma Foundation (\#2009-SCI-MA-684), the Canadian Institutes of Health Research (\#86521) and the Spinal Cord Injury Solutions Network (RHI) (\#2010-43). Toronto Rehab-UHN receives funding from the Ontario Ministry of Health and Long-Term Care. TC is supported by Fellowship Salary Support Award of Spinal Cord Injury-Ontario. LG is the recipient of a Canadian Institutes of Health Research New Investigator Award and an Early Researcher Award from the Ministry of Research and Innovation, and infrastructure funding from the Canadian Foundation for Innovation and the Ontario Research Fund. BC is supported by a CHNF Senior Scientist Award. The views expressed herein do not necessarily reflect those of the funders.

1 Morse L, Teng YD, Pham L, Newton K, Yu D, Liao WL et al. Spinal cord injury causes rapid osteoclastic resorption and growth plate abnormalities in growing rats (SCl-induced bone loss in growing rats). Osteoporos Int 2008; 19: 645-652.

2 Maïmoun L, Couret I, Mariano-Goulart D, Dupuy AM, Micallef J-P, Peruchon E et al. Changes in osteoprotegerin/RANKL system, bone mineral density, and bone biochemicals markers in patients with recent spinal cord injury. Calcif Tissue Int 2005; 76: 404-411.

3 Jiang S-D, Dai L-Y, Jiang L-S. Osteoporosis after spinal cord injury. Osteoporos Int 2006; 17: 180-192.

4 Kanis JA, Adachi JD, Cooper C, Clark P, Cummings SR, Diaz-Curiel M et al. Standardising the descriptive epidemiology of osteoporosis: recommendations from the Epidemiology and Quality of Life Working Group of IOF. Osteoporos Int 2013; 24 : 2763-2764.

5 Garland D, Adkins R, Stewart C. The natural history of bone loss in the lower extremity of complete spinal cord-injured males. Top Spinal Cord Inj Rehabil 2005; 11 : 48-60.

6 Zehnder $\mathrm{Y}$, Lüthi M, Michel D, Knecht $\mathrm{H}$, Perrelet R, Neto I et al. Long-term changes in bone metabolism, bone mineral density, quantitative ultrasound parameters, and fracture incidence after spinal cord injury: a cross-sectional observational study in 100 paraplegic men. Osteoporos Int 2004; 15: 180-189.

7 Craven BC, Giangregorio L, Robertson L, Delparte JJ, Ashe MC, Eng JJ. Sublesional osteoporosis prevention, detection, and treatment: a decision guide for rehabilitation clinicians treating patients with spinal cord injury. Crit Rev Phys Rehabil Med 2008; 20: 277-321.

8 Craven BC, Lynch CL, Eng JJ. In: Eng JJ, Teasell RW, Miller WC, Wolfe DL, Townson AF, Hsieh JTC, et al. (eds). Spinal Cord Injury Rehabilitation Evidence, Version 5.0. SCIRE: Vancouver, BC, Canada. 2014, pp 1-37.

9 Papaioannou A, Morin S, Cheung AM, Atkinson S, Brown JP, Feldman S et al. 2010 clinical practice guidelines for the diagnosis and management of osteoporosis in Canada: summary. CMAJ 2010; 182: 1864-1873.

10 Leslie WD, Lix LM, Langsetmo L, Berger C, Goltzman D, Hanley DA et al. Construction of a FRAX ${ }^{\circledR}$ model for the assessment of fracture probability in Canada and implications for treatment. Osteoporos Int 2011; 22: 817-827.

11 Lentle B, Cheung AM, Hanley DA, Leslie WD, Lyons D, Papaioannou A et al. Osteoporosis Canada 2010 guidelines for the assessment of fracture risk. Can Assoc Radiol J 2011; 62: 243-250.

12 Leslie WD, Berger C, Langsetmo L, Lix LM, Adachi JD, Hanley DA et al. Construction and validation of a simplified fracture risk assessment tool for Canadian women and men: results from the CaMos and Manitoba cohorts. Osteoporos Int 2011; 22: 1873-1883.

13 Marshall $\mathrm{D}$, Johnell $\mathrm{O}$, Wedel $\mathrm{H}$. Meta-analysis of how well measures of bone mineral density predict occurrence of osteoporotic fractures. BMJ 1996; 312: 1254-1259.

14 Cranney A, Wells G, Willan A, Griffith L, Zytaruk N, Robinson V et al. Meta-analyses of therapies for postmenopausal osteoporosis. II. Meta-analysis of alendronate for the treatment of postmenopausal women. Endocr Rev 2002; 23: 508-516.

15 Cranney A, Tugwell P, Adachi J, Weaver B, Zytaruk N, Papaioannou A et al. Meta-analyses of therapies for postmenopausal osteoporosis. III. Meta-analysis of risedronate for the treatment of postmenopausal osteoporosis. Endocr Rev 2002; 23: 517-523.

16 Cranney A, Tugwell P, Zytaruk N, Robinson V, Weaver B, Adachi J et al. Meta-analyses of therapies for postmenopausal osteoporosis. IV. Meta-analysis of raloxifene for the prevention and treatment of postmenopausal osteoporosis. Endocr Rev 2002; 23: 524-528.

17 Craven BC, Robertson L, McGillivray C, Adachi JD. Detection and treatment of sublesional osteoporosis among patients with chronic spinal cord injury. Top Spinal Cord Inj Rehabil 2009; 14: 1-22.

18 Garland DE, Adkins RH, Kushwaha V, Stewart C. Risk factors for osteoporosis at the knee in the spinal cord injury population. J Spinal Cord Med 2004; 27: 202-206.

19 Eser P, Frotzler A, Zehnder Y, Denoth J. Fracture threshold in the femur and tibia of people with spinal cord injury as determined by peripheral quantitative computed tomography. Arch Phys Med Rehabil 2005; 86: 498-504.

20 Vestergaard $\mathrm{P}$, Krogh K, Rejnmark L, Mosekilde L. Fracture rates and risk factors for fractures in patients with spinal cord injury. Spinal Cord 1998; 36: 790-796.

21 Garland D, Adkins R, Stewart C. Fracture threshold and risk for osteoporosis and pathologic fractures in individuals with spinal cord injury. Top Spinal Cord Inj Rehabil 2005; 11: 61-69. 
22 Slade JM, Bickel CS, Modlesky CM, Majumdar S, Dudley GA. Trabecular bone is more deteriorated in spinal cord injured versus estrogen-free postmenopausal women. Osteoporos Int 2005; 16: 263-272.

23 Parsons KC, Lammertse DP. Rehabilitation in spinal cord disorders. 1. Epidemiology, prevention, and system of care of spinal cord disorders. Arch Phys Med Rehabil 1991; 72: S293-S294.

24 Ragnarsson KT, Sell GH. Lower extremity fractures after spinal cord injury: a retrospective study. Arch Phys Med Rehabil 1981; 62: 418-423.

25 Freehafer AA. Limb fractures in patients with spinal cord injury. Arch Phys Med Rehabil 1995; 76: 823-827.

26 Morse LR, Battaglino RA, Stolzmann KL, Hallett LD, Waddimba A, Gagnon D et al. Osteoporotic fractures and hospitalization risk in chronic spinal cord injury. Osteoporos Int 2009; 20: 385-392.

27 Carbone LD, Chin AS, Lee TA, Burns SP, Svircev JN, Hoenig HM et al. The association of opioid use with incident lower extremity fractures in spinal cord injury. J Spinal Cord Med 2013; 36: 91-96.

28 Carbone L, Chin AS, Lee TA, Burns SP, Svircev JN, Hoenig $\mathrm{H}$ et al. The association of anticonvulsant use with fractures in spinal cord injury. Am J Phys Med Rehabil 2013; 92: 1037-1046-1050.

29 Lala D, Craven BC, Thabane L, Papaioannou A, Adachi JD, Popovic MR et al. Exploring the determinants of fracture risk among individuals with spinal cord injury. Osteoporos Int 2014; 25: 177-185.

30 Brown JP, Josse RG, Scientific Advisory Council of the Osteoporosis Society of Canada. 2002 clinical practice guidelines for the diagnosis and management of osteoporosis in Canada. CMAJ 2002; 167: S1-34.
31 Giangregorio LM, Craven BC, Webber CE. Musculoskeletal changes in women with spinal cord injury: a twin study. J Clin Densitom 2005; 8: 347-351.

32 Baim S, Binkley N, Bilezikian JP, Kendler DL, Hans DB, Lewiecki EM et al. Official positions of the International Society for Clinical Densitometry and executive summary of the 2007 ISCD Position Development Conference. J Clin Densitom 2008; 11 : 75-91.

$33 \mathrm{Sim}$ J, Wright CC. The kappa statistic in reliability studies: use, interpretation, and sample size requirements. Phys Ther 2005; 85: 257-268.

34 Kirshblum SC, Burns SP, Biering-Sorensen F, Donovan W, Graves DE, Jha A et al. International standards for neurological classification of spinal cord injury (Revised 2011). J Spinal Cord Med 2011; 34: 535-546.

35 Langsetmo L, Goltzman D, Kovacs CS, Adachi JD, Hanley DA, Kreiger N et al. Repeat low-trauma fractures occur frequently among men and women who have osteopenic BMD. J Bone Miner Res 2009; 24: 1515-1522.

36 Gifre L, Vidal J, Carrasco J, Portell E, Puig J, Monegal A et al. Incidence of skeleta fractures after traumatic spinal cord injury: a 10-year follow-up study. Clin Rehabil 2014; 28: 361-369.

37 Pelletier CA, Dumont FS, Leblond J, Noreau L, Giangregorio L, Craven BC. Self-report of one-year fracture incidence and osteoporosis prevalence in a community cohort of Canadians with spinal cord injury. Top Spinal Cord Inj Rehabil 2014; 20 . 302-309.

38 Bethel M, Weaver FM, Bailey L, Miskevics S, Svircev JN, Burns SP et al. Risk factors for osteoporotic fractures in persons with spinal cord injuries and disorders. Osteoporos Int 2016; 27: 3011-3021. 